\title{
Retracted Article: Association of physical fitness with health-related quality of life in Finnish young men
}

\author{
Arja Häkkinen - Marjo Rinne - Tommi Vasankari • \\ Matti Santtila • Keijo Häkkinen · Heikki Kyröläinen
}

Accepted: 12 January 2010/Published online: 10 February 2010

(C) Springer Science+Business Media B.V. 2010

This article has been published OnlineFirst, but is withdrawn. This action is necessary due to unfortunate errors on both sides (authors and the journal of Quality of Life Research), since this article was originally submitted for publication to another journal and during the review process it was accidentally switched unintentionally to the journal of Quality of Life Research.

\section{A. Häkkinen}

Department of Physical Medicine and Rehabilitation,

Central Hospital, Jyväskylä, Finland

\author{
A. Häkkinen $(\bowtie)$ \\ Department of Health Sciences, University of Jyväskylä, \\ PL 35, 40014 Jyväskylä, Finland \\ e-mail: arja.hakkinen@jyu.fi \\ M. Rinne - T. Vasankari \\ UKK Institute for Health Promotion Research, Tampere, Finland \\ T. Vasankari \\ The National Institute for Health and Welfare, Helsinki, Finland \\ M. Santtila \\ Defence Command, Personnel Division, Finnish Defence Forces, \\ Helsinki, Finland
}

K. Häkkinen · H. Kyröläinen

Department of Biology of Physical Activity,

University of Jyväskylä, Jyväskylä, Finland 